\title{
Ventilation rates in schools
}

\author{
Article
}

Accepted Version

Clements-Croome, D. J., Awbi, H. B., Bako-Biro, Z., Kochhar, N. and Williams, M. (2008) Ventilation rates in schools. Building and Environment, 43 (3). pp. 362-367. ISSN 03601323 doi: https://doi.org/10.1016/j.buildenv.2006.03.018 Available at https://centaur.reading.ac.uk/14118/

It is advisable to refer to the publisher's version if you intend to cite from the work. See Guidance on citing.

To link to this article DOI: http://dx.doi.org/10.1016/j.buildenv.2006.03.018

Publisher: Elsevier

All outputs in CentAUR are protected by Intellectual Property Rights law, including copyright law. Copyright and IPR is retained by the creators or other copyright holders. Terms and conditions for use of this material are defined in the End User Agreement.

\section{$\underline{\text { www.reading.ac.uk/centaur }}$}

\section{CentAUR}

Central Archive at the University of Reading

Reading's research outputs online 


\section{Ventilation rates in schools and pupils' performance}

Zs. Bakó-Birób ${ }^{\text {, D.J. Clements-Croome }}{ }^{\text {a,* }}$, N. Kochhar ${ }^{a}$, H.B. Awbi ${ }^{a}$, M.J. Williams ${ }^{c}$

a The University of Reading School of Construction Management and Engineering, United Kingdom

b Monodraught Ltd, United Kingdom

C The University of Reading Department of Psychology, United Kingdom

Corresponding author, E-mail address: d.j.clements-croome@reading.ac.uk (D.J. Clements-Croome).

\section{Abstract}

This paper is a development of our earlier work $[5,6,11]$. The effects of classroom ventilation on pupils' performance were investigated in 8 primary schools in England. In each school the concentrations of carbon dioxide and other parameters were monitored for three weeks in two selected classrooms. In 16 classrooms interventions were made to improve the ventilation rate and maintain the temperature within an acceptable range using a purpose-built portable mechanical ventilation system. As a result of the interventions the provision of outdoor air to the classrooms was improved from the prevailing levels of about $1 \mathrm{l} / \mathrm{s}$ per person to about $8 \mathrm{l} / \mathrm{s}$ per person.

The pupils and teachers in the classrooms studied were usually exposed to unacceptably poor air quality conditions, with $\mathrm{CO} 2$ concentrations of up to 5000 ppm, much higher than the average recommended levels of $1500 \mathrm{ppm}$ and the preferred level of $1000 \mathrm{ppm}$.

The results of computerized performance tasks performed by more than 200 pupils showed significantly faster and more accurate responses for Choice Reaction (by 2.2\%), Colour Word Vigilance (by 2.7\%), Picture Memory (by $8 \%$ ) and Word Recognition (by 15\%) at the higher ventilation rates compared with the low ventilation conditions.

The present investigation provides strong evidence that low ventilation rates in classrooms significantly reduce pupils' attention and vigilance, and negatively affect memory and concentration. The physical environment therefore affects teaching and learning. 


\section{Background}

Schools in the UK house about 10 million pupils [14,15] who spend almost $30 \%$ of their life in schools and about $70 \%$ of their time inside a classroom during school days. As such, classrooms are the second most important indoor environment for children, after their homes, where they are exposed to various airborne pollutants to a much greater extent than outdoors. Compared to adults, children are more vulnerable to environmental pollutants as they breathe more, relative to their body weight, and are also less well able to deal with toxic chemicals $[17,32]$.

Former reviews on the subject of school environments indicated that ventilation is often inadequate in classrooms, causing an increased risk for asthma and other health related symptoms among school children [13,25]. Actions have been proposed for existing and future school buildings to include adequate outdoor ventilation, control of moisture, and avoidance of indoor exposures to pollutants such as microbiological particles, allergens and chemical substances which are considered likely to have adverse effects.

The current ventilation standards and guidelines $[2,3,9]$ recommend a minimum ventilation rate of $8 \mathrm{l} / \mathrm{s}$ per person in all teaching facilities. Building Bulletin 101 (2006) [8] (the UK Regulatory Framework for schools), the European Standard pr EN15251 (not specifically for schools but the monitoring approach here aligns with its recommendations which are also confirmed in the work of [7]) and REHVA Guidebook 13 [1], refer to proposed performancebased standards limiting the level of carbon dioxide (CO2) concentration to 1500 ppm over a full school day from 9:00 to 15:30 and specify a minimum ventilation rate of $3 \mathrm{l} / \mathrm{s}$ per person in all teaching and learning spaces when they are occupied. Furthermore, a ventilation rate of $8 \mathrm{l} / \mathrm{s}$ per person should be achievable under the control of occupants, although it may not be required at all times if the occupancy density decreases.

A number of studies have also reported that ventilation rates in schools are often substandard, and it is not unusual to find CO2 levels above 3000 ppm in classrooms $[16,24]$. The quality of the classroom environment not only affects health and comfort ([26,35]; Norbäck and Nordström, 2008), but it may also impair the learning performance of pupils. Following earlier studies which indicated such a correlation [27,31], there is growing evidence to show that impairment of learning performance and increased absenteeism are partly due to inadequate ventilation and unsuitable thermal conditions in classrooms $[7,12,18,27,29,30,33,34]$.

Coley and Greeves (2007) [7] carried out a study on how ventilation rates affect cognitive performance in a primary school and reported in their words: "The effects are best characterised by the power of attention factor which represents the intensity of concentration at a particular moment with faster responses reflecting higher levels of focused attention. Increased levels of CO2 from a mean of 690 ppm to a mean of $2909 \mathrm{ppm}$ 
lead to a detriment in power of attention of about $5 \% . "$

Satish et al. (2011) [29] tested the effects of CO2 levels on decision making and concluded that at levels of $2500 \mathrm{ppm}$ and even lower the performance of decision making becomes marginal and in some cases dysfunctional. This work is very interesting as it was carried out by an interdisciplinary team which included people with environmental, medical and management skills and has implications for all buildings [29]. The evidence is growing which suggests that more generally we need to increase public awareness about limiting $\mathrm{CO} 2$ levels in buildings and also on transport systems so promoting freshness and so creating less fatiguing air environments in which we live and work.

On the other hand, achieving adequate ventilation to provide a healthy and comfortable classroom environment without impairing the learning performance of children has inevitable implications for the energy performance of school buildings. It is a delicate balance for every building designer to ensure that the design meets both ventilation and energy performance requirements. However, apart from achieving the ventilation criteria there also seems to be a large difference between the intended (designed) levels of energy performance and the actual performance in use. According to LessEn (an initiative of the international Urban Land Institute), which issued a league table in 2010 showing the energy efficiency of local authority schools in the UK, of 11,993 schools, only 29 had the top energy rating whilst 1703 had the lowest.

Whilst recognising the importance of creating a low carbon economy, this must not be achieved at the expense of neglecting human needs. Schools are for teaching and learning and if these are impaired by poor environmental conditions, then these cannot be considered as sustainable, irrespective of their energy performance.

\section{Aims and objectives}

The purpose of the research was to establish a direct link between pupils' health, well-being and cognitive performance, and the indoor air quality in a sample of primary school classrooms near Reading in the UK and to examine the suitability of the air quality guidelines.

This paper focuses on the indoor air quality in classrooms by using $\mathrm{CO} 2$ as an indicator of ventilation and shows how it affects the performance of mental tasks using in-situ direct measurements.

\section{Methods}

The field surveys were completed over a period, starting in February, 2006 to 2008. The measurements were carried out in eight schools (referred as S1-S8 from hereon), during winter $(\mathrm{S} 1, \mathrm{~S} 7)$, spring $(\mathrm{S} 2, \mathrm{~S} 8)$, early summer $(\mathrm{S} 3, \mathrm{~S} 4)$ and autumn $(\mathrm{S} 5, \mathrm{~S} 6)$. All schools were built in the last $20 \mathrm{e} 40$ years. Except for one school, none had a mechanical ventilation system; in most schools staff had no control over the temperature. At each 
selected school, investigations were carried out in two classrooms for at least three consecutive weeks. The first week was reserved for monitoring the classroom conditions without modifying any of the indoor climatic parameters, and to familiarise the children with the performance tests. During the second and third weeks, a purpose-built mobile ventilation system was installed in each classroom to control the ventilation rate and maintain the temperature within certain limits. The system was set either to provide outdoor air or to re-circulate the classroom air. Although the ventilation system was visible, the staff and the children were not informed about whether it was providing fresh air or re-circulated air. The order of provision of fresh air/re-circulated air conditions was made in a cross-over repeated-measures design for the two classrooms; order of presentation of the two ventilation conditions in the weeks two and three was balanced within the two classrooms in a school and across allschools.

The ventilation system consisted of an exterior fan placed outdoors; a ductwork with a diameter of $200 \mathrm{~mm}$ supplied the air into the building through window openings, which were covered with Perspex plates and cut to connect to the ducts (Fig. 1).

In the classrooms, the air was distributed using Softflo air terminal units, which consist of a perforated duct with small nozzles creating confluent jets flowing into the room [10]. The temperature of the supply air was controlled by means of a duct heater ( $3 \mathrm{~kW})$ and a mobile air conditioning unit of $2.7 \mathrm{~kW}$ connected to the ventilation system. The capacity of the supply fan was selected to provide $200 \mathrm{l} / \mathrm{s}$, matching the prescribed level of $8 \mathrm{l} / \mathrm{s}$ per person in a classroom holding, on average, 25 children. Sound attenuators were also built into the system upstream and down- stream of the fan to reduce the soundbreakout from the ductwork into the classroom. The rating for the AC unit was based on the thermal performance of a typical classroom; the classrooms were all similar in size and construction.
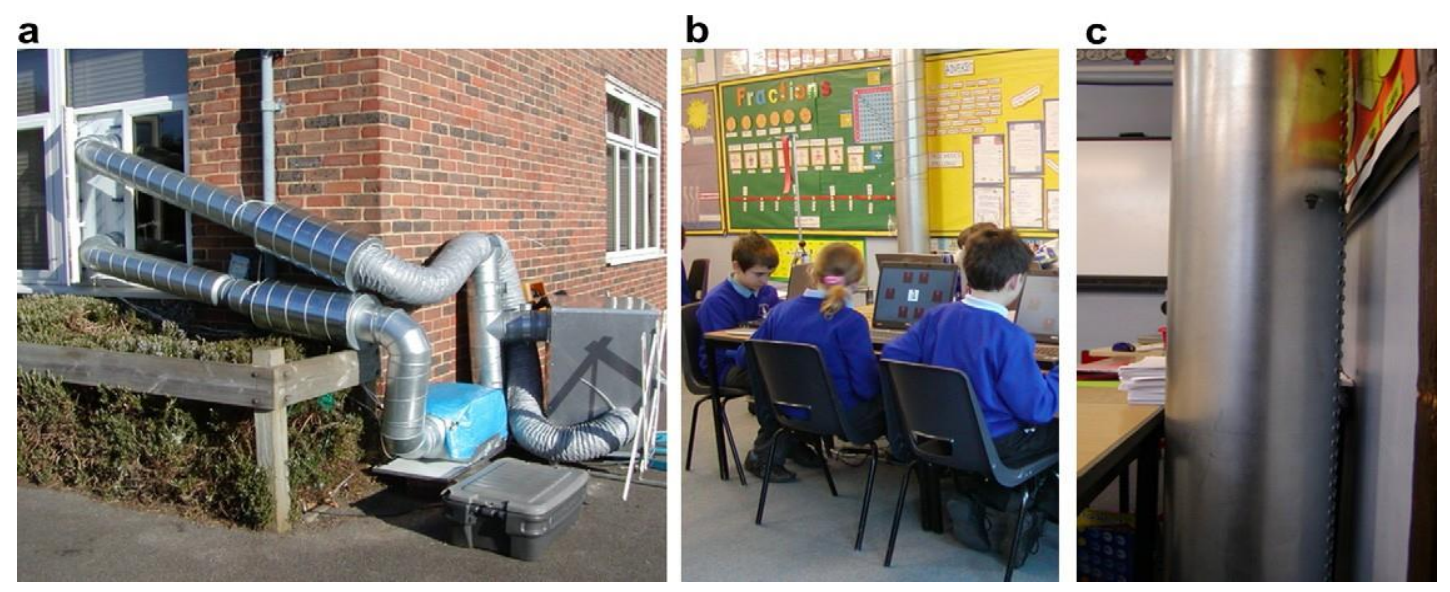

Fig. 1. Exterior fan of the mobile ventilation system (a); testing area with the measuring trolley in the background (b) and air terminal device (c). 

The mobile ventilation system was fully developed only after the measurements in the third school had been completed. Therefore in the first three schools the ventilation system was used only to supply the outdoor air to the classrooms in a controlled manner; the low ventilation condition was obtained with the windows closed. The maximum concentration of $\mathrm{CO}_{2}$ in the re-circulated conditions never exceeded that normally occurring in the classrooms prior to the interventions. During experiments, the teachers and pupils were allowed to open the windows whenever they needed to, without any encouragement or hindrance by the investigators. The open/closed state of windows and classroom doors was monitored by state loggers.

Physical measurements: CO2 concentration (Vaisala GMP222; 0-5000 ppm \pm 20 ppm and $\pm 2 \%$ of reading), air temperature, relative humidity $(\mathrm{RH})$ (Eltek GD-10; $+5-40^{\circ} \mathrm{C} \pm$ $0.4 \mathrm{~K} ; 10 \%-90 \%, \pm 2 \%$ ), globe temperature (diam $36 \mathrm{~mm}$, probe thermistor; -50 to +150 o C $\pm 0.1 \mathrm{~K}$ ), air velocity (Accusense AVS, $0-1 \mathrm{~m} / \mathrm{s}, \pm 5 \%$ of range) and light level (Skye Instr. SL15 0e4000lx $\pm 3 \%$ of range) were continuously monitored in each classroom and recorded at 3-min intervals on a central logger (Eltek Squirrel) using a wireless data transmission technique. These sensors were fixed on a trolley (Fig. 1b) and placed close to the testing area in the classrooms. In addition three thermistor type temperature probes were distributed on a vertical pole fixed to the trolley to record differences in temperature between the pupils' head and foot levels. Separate units were placed outdoors and in the corridors to measure $\mathrm{CO} 2$ concentration, temperature and $\mathrm{RH}$. The corridor units were providing information about the immediate vicinity of the measured classes but generally there was little risk of cross contamination from corridors as doors were closed for most of the time. The amount of supplied air to the classrooms was measured with Venturi flow metres built into the duct system downstream of the fan. The ventilation rate measurements were conducted using the tracer gas decay method (Brüel\&Kjaer Multi-Gas monitor Innova Type 1302) with SF6 as tracer gas (photoacustic detection limit 0.006 ppm SF6). This tracer gas was selected due to the availability of instrumentation. The measurements took place during school breaks in unoccupied classrooms in schools 5e8. The monitoring procedures were compatible with ISO-16000-1.

Subjective evaluations: Simultaneous to the physical monitoring, measures of selfassessed environmental perception, comfort and health were obtained immediately after the performance tests had been carried out. The pupils were asked to complete a simple questionnaire about the classroom environment, thermal sensation, mood, Sick Building Syndrome (SBS) symptoms and life style, such as level of hunger and quality of sleep during the previous night, factors which are believed to affect concentration and, hence, task performance. The majority of the assessments were made on Visual Analogue scales consisting of a continuous horizontal line with statements at the two endpoints [23] and thermal sensation was recorded on a 7-point PMV scale [4]. With few exceptions, all pupils participated in the testing. The targeted age group of the children was between 9 and 10 years attending Year 5 . This age group of pupils was selected because they remain in their classrooms, and are therefore in the same environment, throughout a school day. 
New software - VISCoPe (Ventilation in Schools and Cognitive Performance) was developed for these tests which uses algorithms that are based on the work of [19] in order to assess changes in pupils' cognitive performance under different air quality conditions in classrooms. The test was designed using a flexible approach to allow pupils some control in conducting it. The test battery included 9 different tests: Simple Reaction Time (RT), Choice RT, Colour Word Vigilance, Addition RT, Digit Span Memory, Digit Classification, DigitSymbol Matching, Picture Memory and Word recognition.

The VISCoPe tests are described, in their order of presentation in Table 1. These tests were conducted on laptops set up in the classroom, using a method similar to that of [7]. The pupils interacted with the software on a standard numerical keypad.

Table 1 Description of VISCoPe tests in their order of presentation.

\begin{tabular}{|c|c|}
\hline Test & Description \\
\hline Simple Reaction Time & $\begin{array}{l}\text { A large, red circle appeared on the screen at irregular intervals. Pupils' task was to press the }<\text { ENTER }>\text { key as fast as they could when the } \\
\text { circle appeared. }\end{array}$ \\
\hline Choice Reaction Time & $\begin{array}{l}\text { A red pointer was displayed on the screen, indicating towards North, East, South or West. Pupils' task was to follow the direction } \\
\text { of the pointer on the keyboard by pressing the appropriate arrow key as fast as they could. }\end{array}$ \\
\hline Colour Word Vigilance & $\begin{array}{l}\text { Colour words: RED, YELLOW, BLUE AND WHITE were shown on screen one at a time at constant intervals. Each time any of these words } \\
\text { was presented it could be written in any one of the colours. Pupils were instructed to press the }<\text { ENTER }>\text { key as fast as possible when there } \\
\text { was a match between the meaning of the word and the colour of the text. }\end{array}$ \\
\hline Addition Reaction Time & $\begin{array}{l}\text { Three digits appeared in the middle of the screen at constant intervals. Pupils were asked to add the digits and indicate the sum as quickly } \\
\text { as possible by pressing the }<\text { ENTER }>\text { key }\end{array}$ \\
\hline Digit Span Memory & $\begin{array}{l}\text { A series of digits were presented one at a time on the screen. When a series was completed a question mark appeared, after which pupils } \\
\text { were supposed to repeat the digits shown in the series in the correct order. Correct response was followed by the next series which was } \\
\text { one digit longer; if the response was incorrect, the last series was then repeated. }\end{array}$ \\
\hline Digit Classification & $\begin{array}{l}\text { Numbers between } 1 \text { and } 20 \text { were presented one at a time on the screen. Pupils' task was to decide whether each digit was either ODD or } \\
\text { EVEN by pressing Number } 1 \text { Key if the number was ODD, Number } 2 \text { Key if the number was EVEN }\end{array}$ \\
\hline Digit-Symbol Matching & $\begin{array}{l}\text { On the top of the screen there was a row of symbols. The symbols were paired with digits which were shown below each symbol. } \\
\text { At the bottom of the screen the same symbols were presented in a mixed order. Pupils were instructed to match the correct number } \\
\text { (from the top row) for each symbol. }\end{array}$ \\
\hline Picture Memory & $\begin{array}{l}\text { Six pictures were shown on the screen for } 2 \mathrm{~s} \text {. Pupils were asked to memorize the location of each picture shown and recall their correct } \\
\text { location by pressing the appropriate number key using the keypad. }\end{array}$ \\
\hline
\end{tabular}

Tests were completed during the lessons at a time arranged with the teacher (which was often before the lunch break). By the time the testing commenced, the $\mathrm{CO}_{2}$ concentrations had reached steady state level with increased ventilation or the higher end of the achievable $\mathrm{CO} 2$ level of the teaching session with re-circulated ventilation. The computer tests lasted for $20 \mathrm{~min}$ and were conducted consecutively with 3-4 groups, each including up to 8 children. Overall, 53 groups of children were tested in the 8 schools, and valid data was obtained from 332 children, participating in both test conditions. During the two testing weeks the performance tasks were carried out on the same weekday and during the same time period for each group of children. A Performance Index (PI) was computed to reflect the error-free reaction time, i.e. the mean processing/reaction time of valid answers divided by the accuracy of responses within a task. Thus a high error rate would increase PI value, the time needed to provide accurate answers.

Since the absolute measures of the individual tasks are at different levels it was convenient to show the performance data on a relative scale, where the performance 
indicator for each task is averaged across the conditions. Consequently, the performance result of the two experimental conditions can be expressed relative to this average, denoted as 1.

\section{Data analysis}

The focus of this study is on the general level of main physical parameters describing the classroom environment during test periods. To evaluate the effect of the two levels of ventilation rates on pupils' performance using the computerized assessment tests, statistical analysis was carried out using a mixed design analysis of variance (ANOVA) with ventilation rate (low or high) as a within- participants factor, and order of presentation and class as between-participant factors (with class nested within order of presentation). Simple comparisons were also made using $t$-test or Wilcoxon matchedpairs for related samples. All values reported in this paper represent $p$-values that are 1tailed tests because we were interested only in results showing improvement in performance with more favourable ventilation conditions. The rejection region for significance was set to be $p<0.05$.

\section{Results}

\subsection{Classroom conditions prior to interventions}

The monitoring week was important to provide background data and guidance for the conditions established during recirculation week. The mean values of environmental parameters during school hours for the monitoring week are shown in Table 2. Further details are provided for the concentration of $\mathrm{CO}_{2}$ and parameters of the thermal environment including standard deviation (SD), and the maximum and upper quartile (75th percentile) values. The air temperature reflects the mean values of the records received from the temperature probes distributed on the vertical pole at the measuring trolley. Other parameters derived from the measured data, such as the operative temperature, vertical temperature difference between head and feet levels, predicted draught rating, predicted mean vote (PMV) and predicted percentage of dissatisfied due to thermal environment are also included. The PMV calculations were made for each data point (3-min intervals during occupied period) assuming 1.2 met (school activity) and 0.9 clo (clothing insulation) for a typical pupils' clothing. Although the assumption of 1.2 met activity may not always be a representative value for the whole duration of these tests, it is a value that is often used for children under sedentary activity (ISO 7730) [21]. Unfortunately the outdoor measurements at some schools were not available due to technical failures.

\subsection{Classroom conditions during performance tests}

Fig. 2 and Fig. 3 show the records of the mean $\mathrm{CO} 2$ concentration and globe temperature 
in 16 classrooms of 8 schools measured during completion of the performance tests. The classrooms with mean volume of $154 \pm 15 \mathrm{~m} 3$ and floor area of $58 \pm 5 \mathrm{~m} 2$ were occupied by $25 \pm 4$ children. The carbon dioxide production (12.4 $\pm 0.6 \mathrm{l} / \mathrm{h}$ per person) in the occupied class was calculated according ISO standard 8996 based [20]] on the measured body parameters of children (ADuBois $1 / 41.15 \pm 0.05 \mathrm{~m} 2$ ) at normal activity levels of 1.2 met and the number of children (and adults) present in the classroom.

Using the $\mathrm{CO} 2$ mass balance model the calculated outdoor air exchange rates corresponding to the $\mathrm{CO} 2$ conditions in Fig. 2 were slightly over 4 per hour with the high ventilation condition.

Excluding Schools 1 and 2 where no significant change in the $\mathrm{CO} 2$ level was obtained, the air exchange rates in the rest of the schools were between 0.3 and 1.7 per hour at low ventilation condition.

According to tracer gas measurements, air exchange rates of $4.0 \pm 0.3 \mathrm{~h}-1$ and $0.6 \pm 0.1 \mathrm{~h}^{-}$ 1 were obtained when the ventilation system was providing fresh and re-circulated air respectively. The mean fresh air supply for every school as measured by a flow metre built into the duct system during improved ventilation was at $166 \pm 12 \mathrm{l} / \mathrm{s},(4.0 \pm 0.4 \mathrm{~h} 1$ air change rates), matching well the levels calculated with the other two methods. Assuming the classroom occupancy and the reported air change rates, the air supply rates per person ranged between 0.6 and $4.0 \mathrm{l} / \mathrm{s} . \mathrm{pp}$ and 5.1-9.6 I/s.pp at low and high ventilation conditions respectively.

Deviations of the globe temperature (Fig. 3) between low and high ventilation rate conditions were on average $0.6 \pm 1.6 \mathrm{~K}$.

To evaluate the main effect of ventilation on the performance indicators of the computerized tests, data from Schools 1 and 2 were excluded from the statistical analysis due to the very small variation of the $\mathrm{CO} 2$ concentrations between the tests. The results of the ANOVAs are summarized in Table 3 for 215 pupils who were present in both experimental conditions, out of 250 participants. The PI which denotes the accurate reaction time for a given test was significantly reduced for Choice RT $(F(1,215)=5.35)$, Colour Word Vigilance $(F(1,204) 1 / 44.54)$ and Word Recognition $(F(1,215)=8.30)$

when the ventilation rate was increased from low to high levels. For the Picture Memory task a similar trend was observed in the variation of $\operatorname{PI} F(1,174)=2.58$, and a significant increase was noted in task accuracy $F(1,174)=4.62$ due to the intervention of increasing the ventilation rate. Because multiple tests are reported here, there is the possibility of inflated Type I errors, so these results should be treated with a little caution. Whenever the effect of practice (order of presentation) was large, this counteracted the effect of ventilation. This happened especially in the case of the addition and digit classification tests. Fig. 4a summarises the results expressed in relative performance, which clearly shows the decrement in performance with re-circulated air contrasting with the improvement when fresh air is supplied.

Additionally, the analysis was extended for school no 2, where temperatures were lower than the existing slightly elevated levels of $25.3 \pm 0.4{ }^{\circ} \mathrm{C}$ to $23.1 \pm 0.8^{\circ} \mathrm{C}$ as a result of the 
interventions. The $\mathrm{CO} 2$ level in this school was controlled by an existing mechanical ventilation system below 1000 ppm; however, the provision of air was made at a constant temperature of $28^{\circ} \mathrm{C}$ due to system failure. The temperature reduction was obtained by mixing preheated but slightly cool outdoor air through the mobile ventilation equipment to bring the thermal environment to an acceptable level.

Based on the analysis of cognitive performance of 36 pupils in school no 2, the PI significantly improved by about $6 \%$ for simple RT $(p<0.03)$, choice RT $(p<0.04)$ and by $8 \%$ for Colour Word Vigilance

$(p<0.001)$.

The analysis of subjective voting from 330 pupils indicated relatively small alterations between the experimental conditions. Most of the beneficial effects of the higher ventilation were related to air freshness, sensation of dryness in the mucous membrane, eye dryness and alertness. However, the level of significance was achieved for a minority of classrooms, which do not permit generalisation of the negative sensory and health-related symptoms associated with low ventilation rates to the whole sample.

Significant alterations in thermal voting of subjects occurred only in two classrooms (S3-A \& S4-A), where the temperature difference between the conditions also justified this outcome. In the other classrooms the pupils could not detect any significant variations in the thermal environment, whether it was ventilated at high or low outdoor supply rates. However, it is worth noting that, with one exception, all thermal votes were distributed on the warm side of the scale, even though the classroom temperatures were at the lower end of the comfort range. Most interestingly, the calculated PMV index according to ISO 7730 was always underestimating subjective ratings which could have been due to uncertainties in the value of the parameters used in the PMV calculations, such us changes in activity and clothing ensembles.

Table 2 Mean values of the main environmental parameters in 8 schools (16 classrooms) based on one week's measurements reflecting existing classroom conditions before any intervention was established. 


\begin{tabular}{|c|c|c|c|c|c|c|c|c|c|c|c|c|c|c|c|c|}
\hline Classroom & $\mathrm{S} 1 \mathrm{~A}$ & S1B & $\mathrm{S} 2 \mathrm{~A}$ & $S 2 B$ & $53 \mathrm{~A}$ & S3B & $54 \mathrm{~A}$ & S4B & $55 \mathrm{~A}$ & S5B & $56 \mathrm{~A}$ & S6B & $57 \mathrm{~A}$ & $57 \mathrm{~B}$ & $58 \mathrm{~A}$ & S8B \\
\hline \multicolumn{17}{|l|}{$\overline{\mathrm{CO}_{2}[\mathrm{ppm}]}$} \\
\hline Mean & 1190 & 1400 & 710 & 791 & 1049 & 1071 & 745 & 644 & 1751 & 1462 & 1630 & 1452 & 2417 & 2833 & 2024 & 1653 \\
\hline SD & 448 & 498 & 182 & 178 & 550 & 291 & 233 & 158 & 1220 & 753 & 613 & 560 & 1066 & 1160 & 1068 & 881 \\
\hline Max & 2844 & 2890 & 1115 & 1245 & 2716 & 2011 & 1495 & 1263 & 5000 & 4890 & 2950 & 2808 & 5000 & 5000 & 4946 & 3944 \\
\hline Q3 & 1418 & 1709 & 838 & 918 & 1262 & 1260 & 872 & 726 & 2516 & 1861 & 2084 & 1809 & 3115 & 3666 & 2671 & 2319 \\
\hline \multicolumn{17}{|l|}{ Air temperature $\left[{ }^{\circ} \mathrm{C}\right]$} \\
\hline Mean & 21.8 & 22.3 & 22.0 & 22.5 & 18.8 & 18.5 & 24.2 & 23.0 & 19.3 & 19.9 & 22.0 & 20.3 & 21.1 & 20.1 & 21.2 & 20.7 \\
\hline SD & 1.5 & 1.9 & 1.7 & 0.9 & 0.9 & 1.3 & 2.0 & 1.9 & 1.8 & 18 & 0.9 & 1.0 & 0.9 & 0.9 & 1.6 & 1.6 \\
\hline Max & 25.8 & 25.8 & 24.6 & 24.4 & 21.3 & 22.1 & 28.6 & 26.6 & 22.7 & 23.7 & 24.2 & 22.3 & 22.6 & 22.1 & 24.1 & 23.7 \\
\hline Min & 17.7 & 15.2 & 16.2 & 20.0 & 16.6 & 15.8 & 20.3 & 20.4 & 15.9 & 15.9 & 19.0 & 17.5 & 18.8 & 17.7 & 16.6 & 16.0 \\
\hline Q3 & 22.6 & 24.0 & 23.4 & 23.1 & 19.3 & 19.1 & 26.0 & 24.1 & 20.6 & 21.3 & 22.6 & 21.1 & 21.7 & 20.7 & 22.6 & 21.9 \\
\hline $\mathrm{RH}[\approx]$ & 35 & 35 & 38 & 37 & 64 & 63 & 53 & 52 & 73 & 68 & 59 & 64 & 62 & 64 & 51 & 50 \\
\hline Air velocity $[\mathrm{m} / \mathrm{s}]$ & 0.07 & 0.09 & 0.08 & 0.08 & 0.06 & 0.06 & 0.14 & 0.08 & 0.06 & 0.07 & 0.08 & 0.06 & 0.09 & 0.06 & 0.06 & 0.06 \\
\hline Light [lux] & 315 & 414 & 359 & 410 & 273 & 232 & 256 & 300 & 211 & 236 & 317 & 291 & 352 & 393 & 186 & 235 \\
\hline Outdoor termp. $\left[\left[^{\circ} \mathrm{C}\right]\right.$ & $\mathrm{n} / \mathrm{a}$ & & 10.7 & & 17.7 & & 23.3 & & 16.3 & & 12.5 & & $\mathrm{n} / \mathrm{a}$ & & $n / a$ & \\
\hline RH outdoors [\%] & $\mathrm{n} / \mathbf{a}$ & & 65.8 & & 70.6 & & 59.6 & & 79.3 & & 86.3 & & $\mathrm{n} / \mathrm{a}$ & & $\mathbf{n} / \mathbf{a}$ & \\
\hline $\mathrm{CO}_{2}$ outdoors [ppm] & $\mathrm{n} / \mathrm{a}$ & & 472 & & 441 & & 424 & & 440 & & 445 & & $\mathrm{n} / \mathrm{a}$ & & $\mathrm{n} / \mathrm{a}$ & \\
\hline Operative temp. $\left.\left.\right|^{-} \mathrm{C}\right]$ & 22.5 & 22.8 & 23.6 & 23.2 & 19.1 & 18.8 & 24.5 & 23.3 & 19.5 & 20.4 & 22.6 & 20.9 & 21.5 & 20.3 & 22.1 & 21.5 \\
\hline$\Delta t$ vertical $\left[{ }^{\circ} \mathrm{C}\right]$ & 2.5 & 2.4 & 3.9 & 1.9 & 1.1 & 0.9 & 0.3 & 0.8 & 0.7 & 0.9 & 1.7 & 1.2 & 2.2 & 1.0 & 3.6 & 3.2 \\
\hline DR [\%] & 6 & 10 & 7 & 7 & 2 & 2 & 17 & 7 & 4 & 8 & 8 & 4 & 9 & 4 & 4 & 4 \\
\hline \multicolumn{17}{|l|}{$\begin{array}{l}\text { PMV } \\
\text { PMV }\end{array}$} \\
\hline Mean & 0.0 & 0.0 & 0.2 & 0.1 & -0.6 & -0.7 & -0.1 & -0.3 & -0.5 & -0.3 & 0.1 & -0.2 & -0.1 & -0.4 & 0.0 & -0.2 \\
\hline SD & 0.4 & 0.4 & 0.3 & 0.2 & 0.2 & 0.3 & 0.6 & 0.6 & 0.5 & 0.5 & 0.3 & 0.3 & 0.2 & 0.2 & 0.4 & 0.4 \\
\hline Max & 0.9 & 1.0 & 0.8 & 0.6 & -0.1 & 0.2 & 1.5 & 0.8 & 0.4 & 0.5 & 1.3 & 0.2 & 0.4 & 0.2 & 0.8 & 0.6 \\
\hline Min & -1.1 & -1.6 & -1.7 & -0.7 & -1.1 & -1.5 & -1.3 & -1.5 & -1.5 & -1.9 & -0.9 & -0.9 & -0.9 & -1.1 & -1.4 & -1.5 \\
\hline $\mathrm{Q}^{3}$ & 0.2 & 0.4 & 0.5 & 0.3 & -0.5 & -0.6 & 0.4 & 0.0 & -0.1 & 0.0 & 0.3 & -0.1 & 0.1 & -0.2 & 0.3 & 0.2 \\
\hline \multicolumn{17}{|l|}{ PPD } \\
\hline Mean & 8 & 9 & 8 & 6 & 14 & 18 & 12 & 15 & 14 & 12 & 7 & 7 & 7 & 9 & 9 & 9 \\
\hline SD & 4 & 6 & 4 & 2 & 5 & 8 & 8 & 9 & 12 & 11 & 3 & 4 & 2 & 4 & 5 & 6 \\
\hline Max & 30 & 55 & 63 & 15 & 30 & 50 & 50 & 52 & 48 & 72 & 41 & 21 & 22 & 31 & 46 & 48 \\
\hline Q3 & 9 & 10 & 10 & 7 & 17 & 23 & 15 & 22 & 19 & 12 & 7 & 8 & 7 & 11 & 10 & 10 \\
\hline
\end{tabular}

Table 3 Performance measures using the computerized assessment tests for Schools 3-8.

\begin{tabular}{|c|c|c|c|c|c|c|c|c|c|c|c|}
\hline \multirow[t]{2}{*}{ Performance Test } & \multirow[t]{2}{*}{ Vent. Rate } & \multicolumn{4}{|c|}{ Performance index } & \multicolumn{3}{|c|}{ Accuracy } & \multicolumn{3}{|c|}{ Reaction time } \\
\hline & & $(\mathrm{sec})$ & Change & $\mathrm{p}_{\text {vent }}$ & porder & (\%) & Change & $\mathrm{p}_{\text {vent }}$ & $(\mathrm{sec})$ & Change & pvent \\
\hline \multirow[t]{2}{*}{ Simple RT } & Low & 0.383 & $3.0 \%$ & 0.119 & 0.001 & $95 \%$ & $1.1 \%$ & 0.099 & 0.360 & $3.0 \%$ & 0.33 \\
\hline & High & 0.372 & & & & $96 \%$ & & & 0.355 & & \\
\hline \multirow[t]{2}{*}{ Choice RT } & Low & 0.816 & $2.2 \%$ & 0.011 & 0.084 & $95 \%$ & $0.5 \%$ & 0.121 & 0.771 & $2.2 \%$ & 0.05 \\
\hline & High & 0.798 & & & & $95 \%$ & & & 0.759 & & \\
\hline \multirow[t]{2}{*}{ Colour Word Vigilance } & Low & 0.859 & $2.7 \%$ & 0.017 & 0.040 & $88 \%$ & $1.0 \%$ & 0.048 & 0.742 & $2.7 \%$ & 0.06 \\
\hline & High & 0.837 & & & & $89 \%$ & & & 0.733 & & \\
\hline \multirow[t]{2}{*}{ Digit Classification } & Low & 1.094 & $-1.6 \%$ & 0.308 & 0.025 & $89 \%$ & $-0.3 \%$ & 0.459 & 0.956 & $-1.6 \%$ & 0.25 \\
\hline & High & 1.112 & & & & $88 \%$ & & & 0.966 & & \\
\hline \multirow[t]{2}{*}{ Addition RT } & Low & 7.8 & $-2.7 \%$ & 0.123 & 0.000 & $94 \%$ & $-0.4 \%$ & 0.158 & 0.007 & $-2.7 \%$ & 0.25 \\
\hline & High & 8.0 & & & & $93 \%$ & & & 0.007 & & \\
\hline \multirow[t]{2}{*}{ Digit Span } & Low & 5.0 & $0.9 \%$ & 0.484 & 0.467 & $87 \%$ & $0.9 \%$ & 0.472 & 4.747 & $0.9 \%$ & 0.18 \\
\hline & High & 5.0 & & & & $88 \%$ & & & 4.601 & & \\
\hline \multirow[t]{2}{*}{ Digit-Symbol Match } & Low & 65.6 & $-1.5 \%$ & 0.346 & 0.411 & $81 \%$ & $0.1 \%$ & 0.441 & 47.2 & $-1.5 \%$ & 0.02 \\
\hline & High & 66.5 & & & & $81 \%$ & & & 49.4 & & \\
\hline \multirow[t]{2}{*}{ Picture memory } & Low & 37.1 & $8.0 \%$ & 0.055 & 0.435 & $55 \%$ & $7.2 \%$ & 0.016 & 16.3 & $8.0 \%$ & 0.25 \\
\hline & High & 34.4 & & & & $60 \%$ & & & 16.4 & & \\
\hline \multirow[t]{2}{*}{ Word recognition } & Low & 4.6 & $14.8 \%$ & 0.002 & 0.195 & $95 \%$ & $0.4 \%$ & 0.271 & 4.3 & $14.8 \%$ & 0.001 \\
\hline & High & 4.0 & & & & $95 \%$ & & & 3.8 & & \\
\hline
\end{tabular}

Note: A positive relative change in the performance measures (D) indicates improvement between the conditions; pvent denotes the effect of ventilation, porder indicates the effect of presentation order of the experimental conditions. 


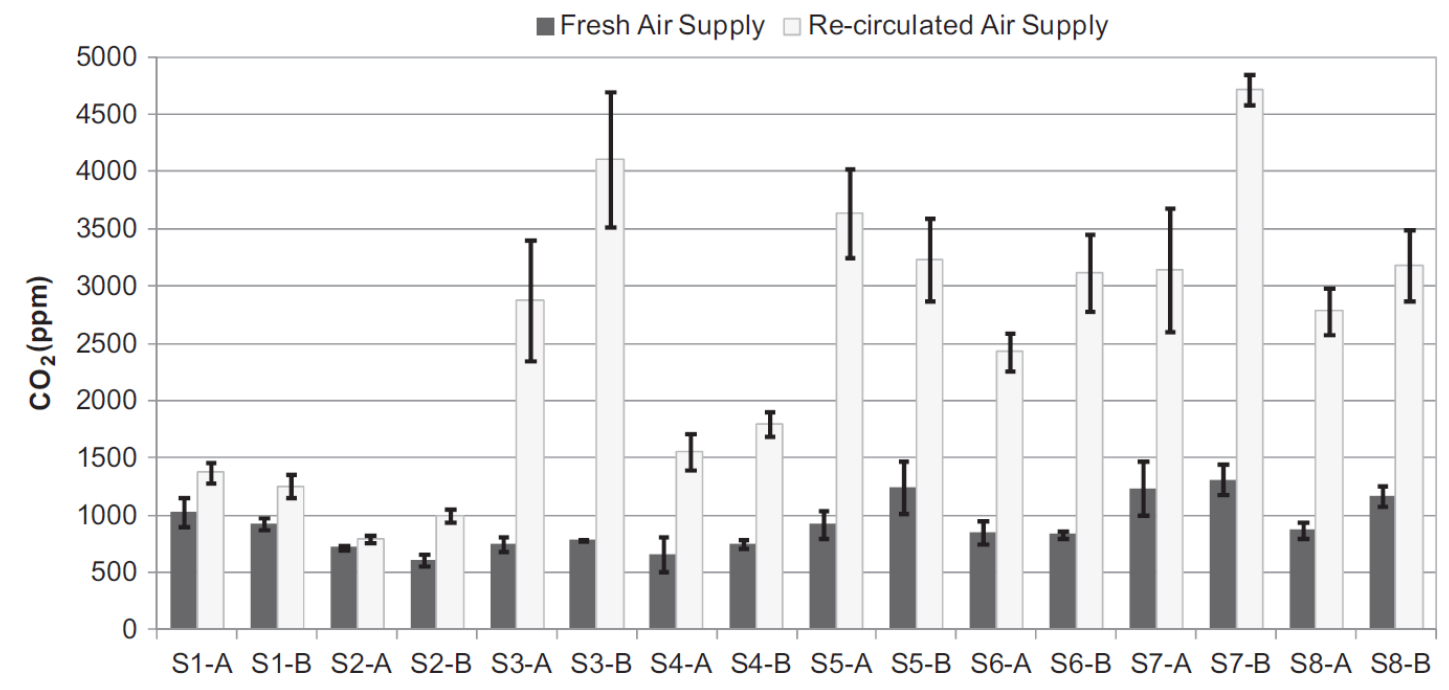

Fig. 2. Mean $\mathrm{CO} 2$ concentrations $( \pm S D)$ during the computerized performance tests in 16 classrooms at 8 schools. Note: For Schools S1 to S3 no recirculation was carried out; the low ventilation condition was obtained by not changing the windows openings unless the teachers decided so.

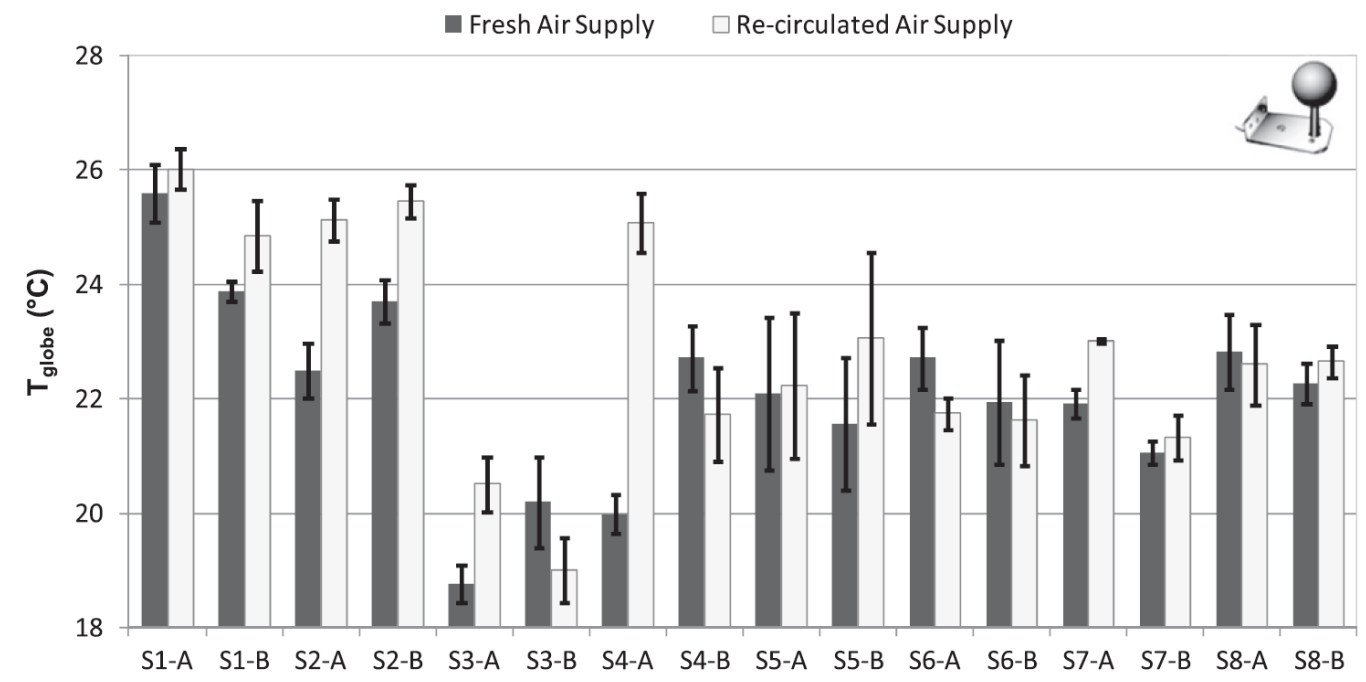

Fig. 3. Globe temperature measurements $( \pm S D)$ during the computerized performance tests in 16 classrooms at 8 schools (3e 4 groups of pupils were tested in each school). 

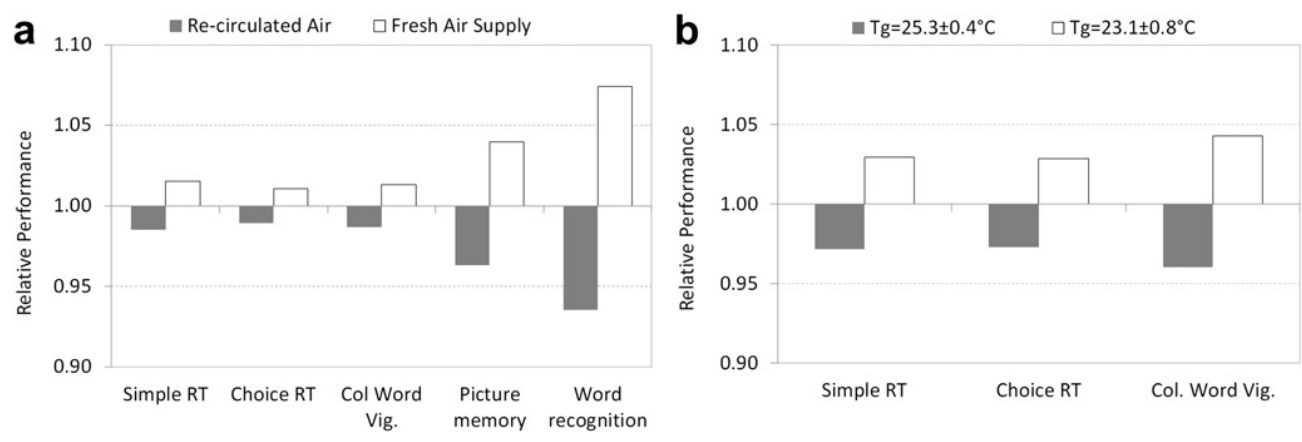

Fig. 4. Relative effects of Ventilation (a) and Thermal environment (b) on Pupil performance and learning.

\section{Discussion}

For the present sample of schools interesting data was obtained during the monitoring week when only physical measurements were made. Considering the average values of $\mathrm{CO}_{2}$ levels in the classrooms, only three classes significantly exceeded the recommended level of 1500 ppm given by BB 101 [1,7]; However, the maximum level reached was as much as 5000 ppm (exceeding the measuring range of the $\mathrm{CO} 2$ sensor), which is at the limit of the occupational health values. The upper percentile concentrations also indicated that a considerable amount of time is spent in much higher concentrations than the average for about half of the classrooms.

The thermal conditions found in the classrooms were satisfactory, but occasionally unpleasant warm conditions were recorded and although only one school was assessed during summer-time, no particularly hot environments were observed. Vertical distribution of the temperatures rarely exceeded $3 \mathrm{~K}$ to cause local discomfort for the occupants, and the air movement was generally too low to cause any draught discomfort. Specific complaints of being too hot were registered from staff in Schools 1 \& 2, which was primarily due to the uncontrollability of the existing HVAC system. This was largely overcome by keeping the windows or fire-doors open, which inevitably contributed to unnecessary energy loss and increase in space heating demand.

The high concentration of $\mathrm{CO} 2$, resulting from extremely low outdoor air exchange rates in the classrooms in which the performance testing, as well as normal teaching activity, was carried out, is striking evidence of efficient building tightness successfully realized to save energy. Double-glazed windows, installed at each of the schools studied, allowed very little air infiltration, indicating a need for an effective means for providing fresh air. Historically, classrooms have relied on air leakage to provide fresh air. In some classrooms, even though the windows were opened (eg. School 1, Class A, Low ventilation condition), the ventilation rate did not exceed $3 \mathrm{l} / \mathrm{s}$ per person. It should be noted that in all classrooms studied, window openings were limited to $20 \mathrm{e} 25 \mathrm{~cm}$ (representing the distance between the movable and fixed frame) to satisfy security requirements demanded by the UK 
Health and Safety Regulations. Many professionals, such as those from the CIBSE Schools Teachers Groups and others, complain about this restriction in hospitals as well as schools as this constraint often prevents adequate ventilation being achieved.

In situations when the windows were left closed, in the absence of other means of providing outdoor air (e.g. when recirculation mode was set), $\mathrm{CO} 2$ levels rose quickly to $3000 \mathrm{e} 4500 \mathrm{ppm}$ within a teaching session. Under such conditions the length of school breaks were often too short to restore $\mathrm{CO} 2$ concentrations to the outdoor levels before the next teaching session commenced. On some occasions, the morning teaching sessions even began with residual $\mathrm{CO}_{2}$ concentration from the previous day. Similar high levels in naturally ventilated classrooms have often been reported in schools in the UK $[12,24]$ and abroad $[7,16]$.

In the current study, the pupils provided their own controls in a repeated-measures design so that the observed differences in performance between conditions are unlikely to have been due to differences between particular groups of children. When calculating the main effect of the ventilation, the present analysis did not assess interactions due to other factors, such as temperature, that may also have contributed in some of the classrooms to the performance outcomes [34]. In this experiment, an effort was made to try to avoid thermal effects due to temperature changes by conditioning the supplied air to maintain the classroom temperature within the comfortable range and also by using a balanced order of presentation of the experimental conditions. In such cases if an external factor, such as change in weather during one of the exposure weeks had affected the study, the effect should have influenced both experimental conditions. The cooling capacity of the portable air conditioning unit, however, was not always sufficient to handle large variations in heat loads. Consequently, a large temperature difference between the test conditions was observed for Class A, School 4, which was not counteracted to the same extent in the other classroom. The observed difference in the thermal environment for this class actually strengthened the influence of ventilation on performance, if we consider that lower temperatures have a positive impact on the performance measures. Indeed such an effect could be demonstrated in School 2, where the air quality conditions were equally good with and without interventions, and the pupils were significantly quicker in performing three different reaction tasks at lower, more comfortable temperatures. In particular, the test session was repeated in Class A in School 4 for the fresh air supply condition at a temperature comparable with that for the re- circulated air condition. However, the results from these repeated tests did not show a significant alteration to the original results of the ANOVA. 
Contrary to expectation, the improved interventions only moderately improved pupils' subjective voting. These interventions were made on a relatively short time scale in order to generate strong effects on health and other symptoms. We should also note that, due to regular school breaks, pupils have more time in each class hour to get away from their classroom and participate in outdoor activities that can compensate for negative health effects due to poor ventilation in the classrooms.

\section{Conclusions and recommendations}

The present study strengthens the evidence reported by [12], but for a larger sample of schools and for over 200 children, that poor ventilation rates in classrooms significantly impair children's attention and vigilance. The faster and more accurate responses in Choice RT and Colour Word Vigilance tasks reflect higher level of focused attention at higher ventilation rates compared to low rates with natural ventilation. In poorly ventilated classrooms, students are likely to be less attentive and to concentrate less well on instructions given by teachers. The magnitude of the negative effects with inadequate ventilation was even higher for tasks that require more complex skills such as spatial working memory and verbal ability to recognize words and non-words. Ventilation rates in the order of $8 \mathrm{l} / \mathrm{s}$ per person are recommended in all teaching facilities to prevent any impairment of pupils' performance due to inadequate ventilation. Additionally, it was demonstrated in one of the schools which had good ventilation background that pupils reacted significantly faster in a number of simple tasks when the classroom temperatures were reduced from existing slightly elevated levels to a more comfortable range. The present findings are in good agreement with the results reported by a number of other independent studies investigating the effects of classroom environmental quality on pupils' learning performance [7,31,34].

Based on the outcomes and observations made during the investigations in the 8 UK schools which involved feedback from teachers, the present study proposes the following suggested recommendations to school managers, designers and related personnel involved in school design and maintenance:

- suggested recommendations for UK schools managers include equipping classrooms with a device to monitor $\mathrm{CO} 2$, temperature \& relative humidity in classrooms; providing additional ventilation if $\mathrm{CO}_{2}$ concentration exceeds 1000 ppm; keeping temperatures within comfortable range of $20-22{ }^{\circ} \mathrm{C}$ (winter) and $22-24{ }^{\circ} \mathrm{C}$ (summer); avoiding moisture build up in classrooms and keeping humidity levels below $60 \%$ during winter time but preferably above 40\%; creating daily windows opening routines for the school; using odorless cleaning agents and remembering that dirty carpets can pollute the indoor environment. 
- suggested recommendations for school building designers, facilities managers and other stake holders include: providing ventilation to limit the concentration of carbon dioxide in all teaching and learning spaces an average of 1000 parts per million (ppm) between the start and finish of teaching on any day, which is lower than the $1500 \mathrm{ppm}$ recommended in the UK's Building Bulletin 101; providing a minimum fresh air supply rate or ventilation rate in all teaching and learning spaces in the order of $8 \mathrm{l} / \mathrm{s}$ per person which falls within the recommendations of $[2,3]$ and other international standards; dedicated ventilation systems may be necessary to achieve the above targets; limiting classroom temperatures to those specified earlier; avoiding overheating by limiting solar gain using utilising passive means such as thermal mass, orientation, fenestration and external/internal shading devices; choice of opening windows and their location are both important in the design of the school façade as this affects the effectiveness of natural ventilation; the high use of computers contributes to an additional heat load but using slim computers with cloud computing, as used by some schools, could radically reduce internal load.

The physical environment affects people's well-being in terms of mind and body. This work shows that elevated level of indoor air pollutants including $\mathrm{CO} 2$ due to inadequate ventilation encountered in classrooms can affect learning. We know that the air we breathe can affect the brain via the blood oxygenation in about $4 \mathrm{~s}$. $\mathrm{CO} 2$ is seen as a harmless gas and so is often accorded little significance, other than as an indicator of ventilation, but if it contributes directly to increased tiredness and a loss of concentration [22] then it might be regarded as a very significant air pollutant. Air quality is just as important as temperature so needs to be monitored so as to guide teachers when to open windows or switch on fans [28].

\section{Acknowledgements}

The project was financed by The Engineering and Physicals Sciences Council (EPSRC), the Department for Communities, Schools and Families (DCSF). Professor P Wargocki at the Technical University of Denmark made a valuable contribution to the project. Professors Anders Iregren (Nat. Inst. for Working Life, Sweden) and David M. Warburton (Department of Psychology, The University of Reading) kindly provided the free use of their test systems for further development. Thanks are also due to Lindab Ltd. for providing free of charge ventilation equipment. The project team is grateful to the Heads of the primary schools for opening their doors to this study and the teachers who participated and liaised with pupils and their parents. Last but not least a special thanks to all the pupils for taking part in the study and providing their comments and suggestions. 
References

[1] d'Ambrosio Alfano, F.R. (ed.), Bellia, L., Boerstra, A., van Dijken, F., Ianniello, E., Lopardo, G., Minichiello, F., Romagnoni, P., Gameiro da Silva, M.C. (2010) Environment and Energy Efficiency in Schools (Part 1), REHVA Guidebook Number vol. 13, REHVA, Brussels, Belgium.

[2] ASHRAE, (2009) Indoor Air Quality Guide (ISBN 978-1-933742-59-5).

[3] ASHRAE. ASHRAE Standard 62.1e2007, Ventilation for Acceptable Indoor Air Quality. Atlanta, GA, USA: ASHRAE; 2007.

[4] ASHRAE Handbook. Fundamentals. Atlanta, USA: American Society of Heating, Refrigerating and Air-Conditioning Engineers, Inc.; 1997.

[5] Bakó-Biró, Zs, Kochhar, N, Clements-Croome, DJ., Awbi, HB. and Williams, M. (2008). Ventilation rates in schools and pupils' performance using computerised assessment tests" Indoor Air 2008, Copenhagen, The 11th International Conference on Indoor Air Quality and Climate.

[6] Bakó-Biró, Zs., Kochhar, N., Clements-Croome, D.J., Awbi, H.B. and Williams, M. (2007) "Ventilation rates in schools and learning performance" In: Proceedings of CLIMA 2007 WellBeing Indoors, The 9th REHVA World Congress, Helsinki, Finland pp. 1434-1440.

[7] Boerstra A, van Dijken Froukje. Indoor environment and energy efficiency of schools. REHVA Journal 2010;47(5):34-8.

[8] Building Bulletin 101 Ventilation of School Buildings. Regulations, Standards, Design Guidance, 2006 July, ISBN 011-2711642.

[9] CIBSE, (2004) CIBSE Guide B: Heating, Ventilating, Air Conditioning and Refrigeration.

[10] Cho Y, Awbi HB, Karimipanah T. Theoretical and experimental investigation of wall confluent jets ventilation and comparison with wall displacement ventilation. Building and Environment 2008;43:1091-100.

[11] Clements-Croome DJ, Awbi HB, Bakó-Biró Zs, Kochhar N, Williams M. Ventilation rates in schools. Building and Environment 2008;43(3):362-7.

[12] Coley DA, Greeves R. The Effect of Low Ventilation Rates on the Cognitive function of a PRIMARY SCHOOL CLASS. Report R102 for DfES, Exeter University; 2004.

[13] Daisey JM, Angell WJ, Apte MG. Indoor air quality, ventilation and health symptoms: an analysis of existing information. Indoor Air 2003;13(1):53-64.

[14] DCSF, (2007) Schools and Pupils in England, SFR30/2007. 
[15] DCSF. Over one billion cash boost to improve school buildings. Press Notice database, http://www.dcsf.gov.uk/pns/DisplayPN.cgi?pn_id1/12005_0115; 2005.

[16] Dijken FV, Bronswijk JV, Sundell J. Indoor environment in Dutch primary schools and health of the pupils. Proceedings of Indoor Air 2005 2005;I(1): 623-7.

[17] Faustman EM, Silbernagel SM, Fenske RA, Burbacher TM, Ponce RA. Mechanisms underlying children's susceptibility to environmental toxicants. Environ. Health Perspect. 2000;108(Suppl. 1):13-21.

[18] Haverinen-Shaughnessy U, Moschandreas DJ, Shaughnessy RJ. Association between substandard classroom ventilation rates and students' academic achievement. Indoor Air 2011;21:121-31.

[19] Iregren A, Gamberale F, Kjellberg A. SPES: a psychological test system to diagnose environmental hazards. Swedish Performance Evaluation System. Neurotoxicology Teratology 1996;18(4):485-96.

[20] ISO 8996 (1990) Ergonomics e Determination of metabolic heat production. [21] ISO 7730. Moderate Thermal Environments e Determination of the PMV and PPD Indices and Specification of the Conditions For Thermal Comfort. Geneva, Switzerland: International Standards Organisation; 2005.

[22] Kajtar L, Herczeg L, Lang E, Hrustinszky T, Banhidi L. Influence of carbon dioxide pollutant on human well being and work intensity. Lisbon, Portugal. In: Healthy Buildings 2006; 2006. p. 85e90.

[23] Kildes $\varnothing$ J, Wyon D, Schneider T, Skov T. Visual analogue scales for detecting changes in symptoms of the sick building syndrome in an intervention study. Scandinavian Journal of Work Environment and Health 1999;25(4):361-7.

[24] Kukadia V, Ajiboye P, White M. Ventilation and indoor air quality in schools, BRE Information paper IP06/05. Watford: BRE publication; 2005.

[25] Mendell MJ, Heath GA. Do indoor pollutants and thermal conditions in schools Influence student performance? A critical review of the literature. Indoor Air 2005;15(1):27-52.

[26] Mi Y-H, Norbäck D, Tao J, Mi Y-L, Ferm M. Current asthma and respiratory symptoms among pupils in Shanghai, China: influence of building ventilation, nitrogen dioxide, ozone, and formaldehyde in classrooms. Indoor Air 2006; 16(6):454-64.

[27] Myhrvold AN, Olsen E, Lauridsen O. Indoor environment in schools epupils health and performance in regard to $\mathrm{CO} 2$ concentrations. Proceedings of the 7th International Conference on Indoor Air Quality and Climate -Indoor Air 1996 1996;4:369-74.

[28] OSHA. In: Indoor Air Quality, Section 3, Chap. 2. Technical Manual, Occupa- tional Safety and Health Administration US (TED 01-00-015); 1999.

[29] Satish, U., Fisk, W.B., Mendell, M.J., Eliseeva, K., Hotchi, T., Sullivan, D., Cleckner, L.B., Shekhar, K. and Teng, K. (2011) Impact of CO2 on Human Decision Making and 
Productivity, Indoor Air Conference June 5-10, Austin, Texas, a 574.

[30] Shendell DG, Prill R, Fisk WJ, Apte MG. Associations between classroom CO2 concentrations and student attendance in Washington and Idaho. Indoor Air 2004;14(5):333-41.

[31] Smedje G, Norback D, Edling C. Mental performance by secondary school pupils in relation to the quality of Indoor air. Proceedings of The 7th International Conference on Indoor Air Quality and Climate e Indoor Air '96 1996; 1:413-9.

[32] Suk W, Murray K, Avakian MD. Environmental hazards to children's health in the modern world. Mutation Research 2003;544:235-42.

[33] Wargocki P, Wyon DP. The effects of outdoor air supply rate and supply air filter condition in classrooms on the performance of schoolwork by children (1257-RP). HVAC\&R Research 2007a;13(2):165-91.

[34] Wargocki $P$, Wyon DP. The effects of moderately raised classroom temperatures and classroom ventilation rate on the performance of schoolwork by children (1257-RP). HVAC\&R Research 2007b;13(2):193-220.

[35] Zhao ZH, Elfman L, Wang ZH, Zhang Z, Norbäck D. A comparative study of asthma, pollen, cat and dog allergy among pupils and allergen levels in schools in Taiyuan city, China, and Uppsala. Sweden Indoor Air 2006;16(6): 404-13. 